Running Head: Ideology Trumps Self-Interest

\title{
Ideology Trumps Self-Interest: Continued Support for a Political Leader Despite Disappointing Tax Returns
}

\author{
Steve Rathje ${ }^{1 *}$, Azim Shariff $^{2}$, Simone Schnall $^{1}$ \\ ${ }^{1}$ Department of Psychology, University of Cambridge \\ Downing Street Cambridge, UK CB2 3EB \\ ${ }^{2}$ Department of Psychology, University of British Columbia \\ 2136 West Mall, Vancouver, BC V6T 1Z4, Canada
}




\begin{abstract}
People presumably strive to maximize their own benefit whenever possible, so it is puzzling when they vote for leaders who may not have their best interest at heart. We tested whether support for a political leader is diminished when supporters learn they are financially disadvantaged by the leader's policies. In a two-stage experiment (Time $1 n=601$, Time $2 n=$ 343) with pre-registered hypotheses, Trump voters predicted their expected tax refund (or payment), and then reported their tax outcome immediately after the filing deadline. Afterwards, we confronted half of the participants with the discrepancy between their actual and predicted tax outcome. Having lower-than-expected tax outcomes was not associated with reduced support for Trump either on its own, or in combination with being reminded of this outcome. However, it led participants who were dissatisfied with their tax outcome to downgrade the importance of lowering taxes, possibly in an effort to reduce dissonance and justify continued support for Trump. Subjective tax outcome satisfaction did predict Trump support, but was dwarfed in magnitude by other variables such as system justification and political orientation. Thus, people may find ways to rationalize information that goes against their self-interest into their partisan world-view.
\end{abstract}

Key Words: Self-Interest, Cognitive Dissonance, Donald Trump, Taxes, System Justification, Leadership 
Ideology Trumps Self-Interest

\section{Ideology Trumps Self-Interest: Continued Support for a Political Leader Despite Disappointing Tax Returns}

"Like a turkey voting for Christmas," is an English idiom that refers to someone supporting actions that might lead to their own demise, which captures the puzzle of why in elections people often appear to vote against their self-interest (Sherrin, 2008). This charge was levied against voters of former United Stated President Donald Trump, who passed a tax law that some had argued would disadvantage his working-class supporters while helping the rich (C.K., 2018). Indeed, a common assumption behind human behavior in many fields, such as economics, is that people tend to maximize their self-interest whenever possible (Hardin, 2015). It therefore is surprising when people seemingly disregard their personal interest when it comes to their political decisions.

In some cases, self-interest has a clear connection to political-decision making. For instance, smokers are more likely to oppose smoking restrictions than non-smokers (Dixon et al., 1991), and homeowners are more likely to oppose property taxes than non-homeowners (Sears \& Citrin, 1982). Additionally, making self-interest salient to participants can lead to more selfinterested political decision-making. For example, priming the importance of their personal benefit led people to favor policies that provided them with greater pay-offs (Young et al., 1991). When people are told to think about the personal costs and benefits of a policy (Chong et al., 2001) or think about the short-term, concrete consequences of a policy (Hunt et al., 2010), selfish reasoning also plays a larger role in decision-making.

However, self-interest can often matter surprisingly little for people's political opinions (Citrin \& Green, 1990; Sears \& Funk, 1990, 1991; Sears, Lau, Tyler, \& Allen, 1980; Slothus \& Bisgaard, 2021). For instance, a person's poor health insurance coverage does not predict their 
support for national health insurance (Sears et al., 1980), and personal unemployment does not affect attitudes about government-guaranteed jobs (Lau \& Sears, 1981). Reviewing the research on self-interest and political attitudes, Lewis-Beck, Norpoth, Jacoby and Weisberg (2008) concluded that "the current scholarly consensus is that self-interest is not a major determinant of issue attitudes" (pp. 197).

In many cases, other values - such as political, cultural, religious, or system-serving values - can override economic self-interest. For instance, 'symbolic politics,' or reactions to political symbols informed by party affiliation, nationalism, or racial prejudice, are much more strongly associated with political preferences than one's current financial situation (Green \& Gerken, 1989; Sears \& Funk, 1991). Cultural and religious values may also supersede economic self-interest. Indeed, while lower-income individuals tend to be more economically liberal, this relationship disappears among the religious (De La O \& Rodden, 2008). Furthermore, party cues (e.g., knowing that one's political party supports a policy) can have a much stronger impact over support for that policy than one's personal stake in it (Slothus \& Bisgaard, 2021). People may also not vote according to their financial situation because they are motivated to view the social structures on which they depend as fair and just, since doing so satisfies fundamental psychological needs - a tendency known as "system justification" (Jost, 2017; Jost et al., 2004; Jost \& Banaji, 1994). For instance, Jost et al. (2017) found little evidence for the intuitive belief that working-class conservative voters in the United States vote for economic policies that seemingly harm their self-interest because they believe that they themselves will someday become rich; instead, system-justifying beliefs predict support for these policies.

If people base their political beliefs on their personal stake in the issues, compromised self-interest should decrease support for a political leader who they believe is responsible for 
their situation. Given past research, this should particularly be the case when self-interest is made salient (Chong et al., 2001). However, given that partisan cues, group-interests, or systemjustifying beliefs often overwhelm the effects of self-interest, it is possible that informing people about a politician's harmful decisions may have no effect.

Moreover, since people may engage in politically-motivated reasoning (Cushman, 2020; Kahan et al., 2007; Kunda, 1990; Van Bavel \& Pereira, 2018), they might find reasons to explain away threats to their self-interest. For instance, learning that one's political preferences contradict one's personal needs could lead to an aversive state of cognitive dissonance, that is, the discomfort that arises from having conflicting attitudes, beliefs, or behaviors (Festinger, 1962; Hart et al., 2009). As a result, this could lead people to downplay the threat to their selfinterest in an effort to reduce this cognitive dissonance. Past research has demonstrated that people interpret factual beliefs about real-world political issues in ways that are consistent with their partisan identity (Gaines et al., 2007; Slothuus \& Bisgaard, 2021). For instance, if people experience worsening economic conditions when their favored party is in power, they will assign less blame to this party (Bisgaard, 2015; Bisgaard \& Slothuus, 2018). Perhaps one reason selfinterest is not strongly predictive of political beliefs is because of people's ability to justify policies that go against their self-interest as not being harmful. We tested this possibility with a very concrete example of a blow to one's self-interest - a disappointing tax outcome.

\section{The Case of Donald J. Trump's Tax Law}

The tax season of 2019 provided an opportunity to test the link between self-interest and support for a political leader. Shortly after Donald Trump became president of the United States in 2016, he passed the Tax Cuts and Jobs Acts of 2017. The White House called the plan the “most significant tax reform enacted in the United States in decades," saying that it would 
provide tax relief for middle-income families, in addition to reducing the corporate tax rate from $35 \%$ to $21 \%$ (Page, Rosenberg, Nunns, Rohaly, \& Berger, 2017). Critics of the tax law, however, cautioned that it would exacerbate income inequality, with tax cuts skewed primarily toward rich individuals and corporations (The Editorial Board, 2017). This led some political commenters to claim that many Trump supporters had in effect voted for a policy that was undermining their own economic self-interest (C.K., 2018).

As people began receiving their tax refunds in early 2019, media sources started to report that many were getting smaller tax refunds than expected (Bernard, 2019). Some suggested that this could hurt support for President Trump. For example, a poll by the New York Times using a nationally representative sample of 4,073 US individuals showed that $65 \%$ of people who said they received a bigger tax refund than the previous year expressed approval of the president, whereas this was only the case of $46 \%$ for those who received about the same refund, and $38 \%$ for those who received a smaller refund (Casselman \& Tankersly, 2019). However, since this evidence was cross-sectional, it is an open question whether compromised self-interest in the form of a disappointing tax refund would actually decrease support for President Trump. Indeed, Trump supporters were resistant to changing their minds in response to learning about his false claims (Swire-Thompson et al., 2019), suggesting that Trump supporters' opinions may be difficult to change.

We tested whether a disappointing tax outcome had a causal effect on Trump voters' support for him and his various policies. We did this by making salient the potential discrepancy between their predicted and actual tax burden across two time points. We asked Trump voters to predict their tax refund or payment about two months before the filing deadline in 2019 (Time 1) and indicate their support of the president and his various policy positions at that point. On the 
day immediately following the filing deadline (Time 2), the same individuals indicated their actual tax outcome and their satisfaction with it.

At Time 2 we also manipulated the salience of people's financial self-interest, to see whether it had a causal effect on their political beliefs. For half the sample, we confronted participants with the potential discrepancy between their predicted and actual tax outcome before they indicated their support for Trump and various policy positions (Reminder Condition). The other half of the sample reported their support before being informed about the potential discrepancy between their predicted and actual tax burden (No Reminder Condition).

We had multiple pre-registered hypotheses, specified here: http://aspredicted.org/blind.php?x=jn9qp2. First, we hypothesized that the more disappointing a person's tax return was relative to their prediction, the greater would be the decline in support for Trump from Time 1 to Time 2. Second, we predicted that confronting Trump voters who received disappointing tax outcomes with the discrepancy between their actual and predicted tax outcomes would lead to a decline in support relative to those in in the control condition. However, we also considered the possibility that an unfavorable tax outcome may be unrelated to Trump support, and that system-justification beliefs and partisanship would be better predictors. In addition, we were interested in how making Trump supporters' financial self-interest salient would influence their policy preferences, with a particular focus on the importance of lowering taxes. On the one hand, being reminded of a disappointing tax return could make participants think that lowering taxes is more important. On the other hand, the manipulation could cause people to downgrade the importance of lowering taxes in an effort to reduce the cognitive dissonance experienced in the face of a disappointing tax outcome. More specifically, based on cognitive dissonance theory (Festinger, 1962), people may avoid holding two 
conflicting thoughts (i.e., "I support Trump" vs. "Trump’s tax policy negatively affected me”) by changing or justifying their attitudes to correspond to their prior beliefs and behavior (i.e., "lowering taxes is not important anyway"). In other words, Trump supporters might revise their political opinions to fit the information about their disappointing tax returns into their partisan world-view.

\section{Method}

\section{Participants.}

Participants were recruited via Amazon Mechanical Turk for a study on "Attitudes and Beliefs" that would take approximately 3 minutes. Data collection for Time 1 began on February 23, 2019 and ended March 3, 2019, about a month and a half before the tax deadline of April 15, 2019. We aimed to recruit a target sample size of 600 participants who met our inclusion criteria, namely 1) residency in the United States, 2) US citizenship, 3) having voted for Donald Trump in the 2016 election and 5) not yet having filed their tax return. Given the possibility of automatized non-human responses on MTurk, we also included a "bot check" in which we had participants solve a simple math problem ("what is 12-8?") at the start of the survey and did not allow participants to continue with the survey if they failed this check. Of the 5683 participants who began the survey, 624 fulfilled these requirements. We excluded 23 participants who did not complete all questions or failed attention checks and another 23 participants who reported that they were "not confident at all" in their tax prediction. Six participants were excluded who said they expected a tax payment greater than $\$ 10,000$, which was outside the range measured on our sliding scale. This left 572 participants who were invited to participate in the Time 2 follow-up survey.

Data collection for Time 2 began on April 16, 2019, the day after the tax filing deadline, 
Ideology Trumps Self-Interest

and ended 3 weeks later on May 7, 2019. After exclusions, we had a final sample of 343

participants $\left(\mathrm{M}=145, \mathrm{~F}=196, \mathrm{M}_{\mathrm{age}}=44.99\right)$ with data for both time points. Participants electronically provided informed consent before completing each survey, and methods were approved by the University of British Columbia Institutional Review Board.

\section{Materials.}

Trump Support. Four questions assessed Trump Support at both time points, adapted from F. Cohen, Solomon, \& Kaplin (2017): How favorably do you view Donald Trump? To what extent do you admire Donald Trump? To what extent do you have confidence in Donald Trump as a leader? If you vote in the 2020 Presidential Election, how likely is it you will vote for Donald Trump? Questions were answered on a nine-point scale ( $1=$ not at all; $5=$ somewhat; $9=$ very much). The four items were averaged to create composite scores of Trump Support at Time $1(\alpha=0.96, M=6.66, S D=2.16)$ and Time $2(\alpha=0.96, M=6.61, S D=2.24)$.

Policy Items. Participants indicated the importance of the following ten policy issues for the country at both time points: increasing the number of jobs, protecting the border, lowering taxes, addressing climate change, reducing governmental corruption, improving access to healthcare, strengthening the military, supporting higher education, combating terrorism, and reducing crime. Items were measured on a nine-point scale $(1=$ not at all important; $9=$ very important) and were presented in a randomized order.

Political Orientation. Political orientation was measured on a 7-point scale $(1=$ Extremely liberal; $7=$ Extremely conservative; $8=$ Don't know $)(M=5.50, S D=1.17)$, adapted from Knoke (1979).

Party Affiliation. Participants indicated party affiliation on a 9-point scale (1 = Strong Democrat; 2 = Not Strong Democrat; 3 = Independent, Near Democrat; 4 = Independent; $5=$ 
Independent, Near Republican; 6 = Not Strong Republican; 7 = Strong Republican; 8 = Other Party; 9 = Don't Know $(M=5.82, S D=1.25)$, adapted from W. E. Miller (1991).

Satisfaction with Tax Outcome. Participants were asked "How satisfied are you with your tax outcome?” on a 9-point scale $(1=$ not at all; $9=$ very $)(M=5.58, S D=2.92)$.

System Justification. Participants answered the 8-item general system justification scale (Kay \& Jost, 2003), which includes items like "Everyone has a fair shot at wealth and happiness" and "The United States is the best country in the world to live in," measured on a 9-point scale (1 $=$ Strongly Disagree; $9=$ Strongly Agree $)(\alpha=0.84, M=5.86, S D=1.40)$.

\section{Procedure.}

Time 1 (Feb 13-March 3, 2019). Participants first completed the four Trump Support items and the 10 items that measured support for various policy positions. Participants were then asked "Do you expect to receive a tax refund this year?" If they answered yes, they indicated via a sliding scale from $\$ 0$ to $\$ 10,000$ : "how much do you predict your tax refund to be this year, once you file your taxes? Please enter your answer in dollars. If you are unsure, please enter your best guess." If they predicted that their tax refund would be greater than $\$ 10,000$ they entered it via a text box below the slider. If participants answered no, they entered their expected tax payment using the same sliding scale or text-box. Afterwards, participants rated how confident they were in their prediction on a 6 -point scale $(1=$ not at all confident; $6=$ very confident $)$. Lastly, participants were asked about demographics, political orientation, and political party affiliation.

Time 2 (April 16-May 7, 2019). We sent participants a follow-up survey immediately after the deadline to complete an income tax return, which was April 15, 2019. Participants were randomly assigned to one of two conditions. In the Reminder Condition, participants were first 
asked "Did you receive a tax refund this year?" If they answered yes, they indicated the amount on the same sliding scale as for Time 1 . Then participants were reminded of the difference between their tax outcome and tax prediction, using the following structure:

"In a previous survey, you predicted you would receive a [tax refund/tax payment] of [participant's predicted amount entered at Time 1]

Instead, you received a [tax refund/tax payment] of [participant's actual outcome entered at Time 2].

In other words, this year's tax outcome was [difference between tax prediction and tax outcome] [more/less] than you expected."

If a participant received exactly the same tax outcome they predicted (which was the case for 33 participants), they were told "your tax outcome was the same as you expected." Immediately below this reminder, participants were asked to indicate how satisfied they were with their tax outcome on a 9 -point scale $(1=$ not at all; $9=$ very $)$. Then they received the same four questions measuring Trump support and the same 10 questions measuring policy preferences as for Time 1.

In the No Reminder Condition, the order of questions was reversed such that participants first indicated their support for Trump and the 10 policies. Afterwards, participants entered their tax outcome and receive the same reminder described above. At the end of the survey all participants (regardless of condition) completed a measure of system justification (Kay \& Jost, 2003) before being debriefed and receiving compensation.

\section{Results}

We computed a tax discrepancy score by subtracting the predicted from the actual tax outcome. A positive tax discrepancy score therefore indicates a tax outcome that was better than 
expected, and a negative tax discrepancy score indicates a tax outcome that was worse than expected. The mean tax prediction was $\$ 584.92(S D=2142.19)$, whereas the mean actual tax outcome was $\$ 201.93(S D=3842.40)$, resulting in a mean tax discrepancy score of $\$-382.99$ (SD $=2760.66)$. Thus, on average, participants were worse off than they expected.

To test whether the discrepancy score was associated with Trump support, we examined the bivariate correlations between the main outcome variables and Support for Trump at Time 1 and at Time 2 (see online supplement for correlation tables, Table S1 and Table S2). The tax discrepancy score was unrelated to Trump support at both time points ( $p s>0.704)$. While subjective satisfaction with one's tax outcome did show a positive correlation with the Trump support composite score at Time $2, r(340)=0.15, p=.005$, this relationship was relatively modest. In contrast, political orientation was a much more powerful predictor, $(r(337)=0.53, \mathrm{p}$ $<.001$ at Time $1 ; r(337)=0.55, p<.001$, at Time 2$)$, as were political party affiliation $(r(331)=$ $0.46, \mathrm{p}<0.001$ at Time $1 ; \mathrm{r}(331)=0.48, \mathrm{p}<0.001$ at Time 2$)$ and system justification, $(r(336)=$ $0.33, p<0.001$ at Time $1 ; r(336)=0.41, p<0.001$ at Time 2$)$. The magnitude of these correlations was substantially greater than the one for subjective tax outcome satisfaction, consistent with our theorizing that political ideology and system justification may overwhelm the effects of self-interest.

Our first pre-registered hypothesis was that the tax discrepancy score would predict support for Trump, and moreover, that there would be an interaction effect such that those who received disappointing tax returns and were reminded of it would show a decrease in support for Trump. Following the pre-registered analysis plan, we ran moderation analyses to look at the effect of the tax discrepancy score and the tax reminder on the main outcome variables. The tax discrepancy score (actual - predicted tax outcome) was the independent variable, the change in 
the Trump support composite score (Time 1 - Time 2) was the dependent variable, and the condition (Reminder vs. No Reminder) was the moderator. Contrary to our prediction, there was no main effect of the tax discrepancy score, $B=0.00, S E=0.00, p=0.621,95 \% \mathrm{CI}=[0.00$, $0.00]$ nor the reminder condition, $B=-0.05, S E=-0.42, p=0.643,95 \% \mathrm{CI}=[-0.13,0.08]$. Importantly, there also was no predicted interaction between the reminder and the tax discrepancy score, $B=0.00, S E=0.00, p=0.670,95 \% \mathrm{CI}=[0.00,0.00]$.

We next ran a second moderation model with the subjective tax satisfaction score as the key independent variable instead of the tax discrepancy score. There was a significant main effect of the satisfaction score on Trump Support change, $B=0.04, S E=0.02, p=0.019,95 \% \mathrm{CI}$ $=[0.01,0.08]$. However, there was no interaction between the reminder condition and the satisfaction score, $B=-0.00, S E=0.02, p=0.946,95 \% \mathrm{CI}=[-0.04,0.04]$. There also was no main effect of the reminder condition $B=-0.03, S E=0.05, p=0.626,95 \%=[-0.13,0.08]$. Altogether, we found that subjectively - but not objectively - dissatisfying tax returns predicted a change in Trump Support, while disappointing tax outcomes salient had no impact.

Our second pre-registered hypothesis was that a reminder of disappointing taxes might lead participants to downgrade the importance of lowering taxes in an effort to reduce cognitive dissonance about their continued support for Trump. We ran the same moderation models as the ones described above, but this time entered the tax policy change score (Importance of Lowering Taxes at Time 2 - Importance of Lowering Taxes at Time 1) as the dependent variable. We expected the tax discrepancy score to predict the tax policy change score, and moreover, for there to be an interaction between the tax policy change score and the reminder condition.

We found no main effect on tax policy importance using the objective tax discrepancy score, $B=0.00, S E=0.12, p=0.353,95 \% \mathrm{CI}=[-0.09,0.25]$, no main effect of the salience 
manipulation, $B=0.00, S E=0.17, p=0.995,95 \% \mathrm{CI}=[-0.17,0.17]$, and no interaction, $B=$ $0.00, S E=0.00, p=0.678,95 \% \mathrm{CI}=[0.00,0.00]$. We ran a second moderation model with the subjective tax return satisfaction score as the independent variable instead of the objective tax return outcome. Here we found a non-significant (but marginal) main effect of the satisfaction score on the "importance of lowering taxes" policy item, $B=0.01, S E=0.04, p=0.086,95 \% \mathrm{CI}$ $=[-0.05,0.06]$, and no main effect of the reminder condition, $B=0.01, S E=0.17, p=0.896$, $95 \% \mathrm{CI}=[-0.16,0.18]$. Importantly, we found the predicted interaction between the satisfaction score and the tax reminder, $B=-0.07, S E=0.06, p=0.014,95 \% \mathrm{CI}=[-0.13,-0.02]$. (see Figure 1, Panel A).

To follow-up on this interaction, we conducted a median split on the satisfaction score. Participants who were dissatisfied with their tax returns and reminded of it $(M=-0.12, S D=$ 1.56) indicated that lowering taxes was marginally less important than those who were not reminded $(M=0.33, S D=1.43), t(170)=1.97, p=0.051, d=0.30$. This provides support for our hypothesis that Trump supporters, when reminded of their disappointing tax outcomes, would downgrade the importance of lowering taxes. For the more satisfied half of participants, the pattern was reversed: the tax reminder led to a marginal increase in the importance of lowering taxes $(M=0.27, S D=1.79)$, as compared to participants in the no reminder condition $(M=$ $0.19, S D=1.54), t(170)=-1.77, p=0.079, d=0.27$.

Because our logic rests on the assumption that this effect should be especially relevant for participants who were highly supportive of Trump yet had a bad tax outcome, we ran exploratory analyses by creating a "dissonance score," whereby we subtracted tax outcome satisfaction from Trump support at Time 2 (i.e., the time by which the tax outcome was known). A high score therefore indicated a greater discrepancy between one's support for Trump and satisfaction with 
their tax return. We entered this dissonance score into another moderation model as predictor, and the change in the importance of lowering taxes policy as the dependent variable, with reminder condition as the moderator. Consistent with the earlier analysis, there was a significant interaction between the dissonance score and reminder condition, $B=0.14, S E=0.05, p=0.006$, such that participants with high dissonance in the reminder condition downgraded the importance of lowering taxes relative to participants in the no reminder condition. To follow-up on this interaction, we conducted another median split on the dissonance score. For the half of participants with the highest dissonance scores - that is, those who showed the most support for Trump and the least satisfaction with their tax return - the reminder condition led to a decrease in the importance of lowering taxes $(M=-0.27, S D=1.47)$ as compared to the no reminder condition $(M=0.35, S D=1.33), t(164)=2.83, p=0.005, d=0.44$. For the half of participants with the lowest dissonance scores, the pattern once again reversed: the reminder condition led to an increase of the importance of lowering taxes $(M=0.40, S D=1.83)$ as compared to the no reminder condition $(M=-0.18, S D=1.62), t(173)=-2.19, p=0.030, d=0.33$. This analysis, while exploratory, bolsters the hypothesis that those who had the largest gap between their support for Trump and satisfaction with their tax outcome dealt with this sense of cognitive dissonance by downplaying the importance of lowering taxes.

We then explored the role that political orientation and system justification played in the relationship between economic self-interest and Trump Support. We first conducted a multiple regression with tax discrepancy score, reminder condition, political orientation, system justification, and the interaction between these variables as predictors of Trump support, measured at Time 2 (we considered Trump Support measured at one time point — rather than a change in Trump Support — to be most relevant in a model that considers relatively stable traits 
such as political orientation and system justification). Then we ran another multiple regression with these same variables and the subjective tax outcome satisfaction score instead of the objective tax discrepancy score (Table 1 and Table 2). In the first model, the tax discrepancy score, the reminder condition, and their interaction were not significant predictors of Trump support at Time 2 ( $p \mathrm{~s}>0.284)$. However, political orientation, $B=0.90, S E=0.09, p<0.001$, $95 \% \mathrm{CI}=[0.73,1.08]$ was a strong independent predictor of Trump support, as was system justification, $B=0.46, S E=0.07, p<0.001,95 \% \mathrm{CI}=[0.32,0.60]$.

In the second model, tax outcome satisfaction was a small but significant predictor of Trump Support at Time 2, even when controlling for other factors, $B=0.09, p=0.044,95 \% \mathrm{CI}=$ $[0.002,0.135]$, though the reminder condition and their interaction were not $(p s>0.463)$.

However, the magnitude of this effect should be put in context: a one-point (out of nine) increase in tax outcome satisfaction was associated with 0.09-point increase in Trump Support, whereas a one-point (out of eight) increase in system justification was associated with a 0.43 -point increase in Trump support, and a one-point (out of eight) increase in political orientation was associated with a 0.87 -point increase in Trump support.

In both models there was a significant interaction between the condition and political orientation $(B=-0.28, S E=0.09, p=0.001,95 \% \mathrm{CI}=[-0.45,-0.11]$ in model $1, B=-0.30, S E=$ $0.09, p=0.001,95 \% \mathrm{CI}=[-0.48,-0.13]$ in model 2$)$, which was not anticipated. Parsing the interaction with a median split indicated that, for the more liberal participants, receiving the reminder led to a marginal decrease in Trump support $(M=5.00, S D=2.29)$ relative to not getting the reminder $(M=5.76, S D=2.45), t(140)=1.93, p=0.056, d=0.32$. For the more conservative participants, the reminder led to an increase in Trump support $(M=7.71, \mathrm{~S} D=$ 1.56), relative to no reminder, $(M=7.25, S D=1.71), \mathrm{t}(199)=1.99, p=0.048, d=0.28$. Since 
we did not predict this interaction and the models tested several different interactions (making it more likely one of them would be significant by chance), it is unclear if this interaction is meaningful. ${ }^{1}$

\footnotetext{
${ }^{1}$ One interpretation of this is that the more conservative participants reacted defensively to the reminder (regardless of the actual content of the reminder), and expressed increased Trump Support in a response to a manipulation that potentially threatens their support. The more liberal participants, on the other hand, may have been less loyal to Trump and more open to shifting their support for him in response to a self-interest reminder. However, if this was the case, we would have expected a three-way interaction such that the reminder had different effects for those who had more or less disappointing tax returns, which was not observed.
} 


\section{Discussion}

In a two-stage experiment before and after the 2019 tax return deadline, we tested whether financial self-interest in the form of a disappointing tax outcome would affect support for president Donald Trump and his various policies. We found no relationship between a disappointing tax outcome (relative to one's prediction) and support for Trump. Even when we directly confronted supporters with their disappointing tax outcomes, it still did not reduce their support for Trump. Although we observed no effect of objective tax outcomes (i.e., specific dollar amount), we did find a small relationship between subjective satisfaction with one's tax outcome and support for Trump. However, to contextualize the relative magnitude of this effect, it was almost five times smaller than that of system justification and almost ten times smaller than that of political orientation.

Importantly, we also found evidence for our pre-registered hypothesis that making tax outcomes salient to those who had received disappointing tax returns would lead Trump supporters to view lowering taxes as less important, presumably in an effort to rationalize their continued support for him. This effect was most pronounced for those who were highly supportive of Trump but had disappointing tax returns - in other words, those who had the most "dissonance" between their support for Trump and their disappointing tax outcomes - further supporting the cognitive dissonance hypothesis. This provides an example of cognitive dissonance in a real-world context, showing that people can justify their support for political leaders who work against their self-interest by revising their beliefs (Festinger, 1962; Hart et al., 2009).

These results fit in with the body of literature suggesting that, in many contexts, selfinterest has limited effects on political decision-making (Sears \& Funk, 1991; Slothus \& 
Bisgaard, 2021), and can be overwhelmed by group-interest, party cues, or system serving beliefs. It also concords with prior findings showing that Trump supporters can be resistant to changing their opinion about Trump in response to negative information about him, such as information about his false claims (Swire-Thompson et al., 2019).

This work significantly adds to this literature on the role of self-interest in political decision-making by demonstrating that people may rationalize events that go against their selfinterest as not actually being harmful. This may help explain why self-interest has a limited connection to political decision-making: instead of people explicitly invoking "group" interests or "symbolic politics" over self-interest, these factors — or even commitment to a particular, charismatic individual — may unconsciously motivate people to justify or explain away events that go against their self-interests if they clash with higher-order commitments. While prior work has looked at partisan bias in perceptions of policy or the economy (Bisgaard, 2015), ours looks specifically at reactions to a disappointing tax returns - a concrete example of financial selfinterest.

Our work also diverges from the results of past experiments that demonstrate that making self-interest salient can make it matter more for political decision-making (Chong et al., 2001; Hunt et al., 2010; Young et al., 1991). Instead of the tax reminder reducing Trump support, the tax reminder appeared to generate a defensive reaction, leading Trump supporters to alter their beliefs to cope with their disappointing tax returns. These results might be because Trump supporters are a particularly loyal population, and are less willing to dislodge their support for Trump in the face of disappointing information. Alternatively, Trump supporters may not have attributed their disappointing tax returns to him directly, but may have attributed the discrepancy between their predicted and actual tax returns to over-optimism, or may simply have not cared as 
much about their taxes as they did about other issues, such as the border wall.

This research is, of course, not without its limitations. While a strength of this study is that it gives us insight into a recent political moment, it is unclear whether these findings would generalize to other time periods, or to other populations besides Trump supporters. Donald Trump may have particularly loyal group supporters who are less willing to give up their support for him. Additionally, due to potential asymmetries between liberals and conservatives in various traits, including need for closure (Federico et al., 2005), intolerance of cognitive dissonance (Collins, Crawford, \& Brandt, 2017), or views about group loyalty (Graham et al., 2009), these results may be different for liberals and conservatives.

Future research could explore boundary conditions behind when such instances of rationalization are likely to occur, and explore whether there are situations that encourage or inhibit rationalization. In our experiment, it may have been relatively easy to explain away an instance of disappointing tax returns because this was a relatively small loss of money and it could have been easier to attribute this to a cause other than Trump. However, if a blow to selfinterest is considerably larger and more difficult to rationalize, self-interest may potentially have a stronger impact. Indeed, prior work has found that there are limits to motivated reasoning, and that people may stop engaging in it if they repeatedly encounter evidence that violates their expectations (Redlawsk et al., 2010). For example, in the context of Donald Trump's presidency, a more significant issue might be his alleged involvement in an attempted coup to overturn the 2020 election results.

In 2016, Donald Trump said that he could "stand in the middle of Fifth Avenue and shoot somebody" and he would still not lose voters (Diamond, 2016). In line with that quote, this study provides evidence for the impregnability of Trump's support in the face of his supporters' 
compromised self-interest. More broadly, it demonstrates that partisan loyalty and system justification can out-weigh self-interest in political decision-making, and that people can rationalize information that goes against their self-interest. Beyond the topic of taxes, this study may also shed light on why Trump supporters maintained their support in spite of the great loss of life because of his policy decisions during the coronavirus pandemic, and why partisan differences in beliefs about the threat of COVID-19 were so strong (Gollwitzer et al., 2020). Partisans may not only disregard financial self-interest, but health self-interest as well. Instead of self-interest informing people's support for a political leader, support for a political leader may come first, shaping how people interpret information that conflicts with their interests. Thus, some people may be adept at revising their beliefs to fit information that goes against their own benefit into their partisan world-view. These results may explain, in part, why it seems as if some people cast their ballots like turkeys voting for Christmas.

\section{Disclosure Statement}

No potential conflict of interest was reported by the authors. 
Ideology Trumps Self-Interest

\section{Funding Statement}

This work was supported by a Gates Cambridge Scholarship to S.R. (Gates Cambridge Trust, Grant \#OPP1144) 
Ideology Trumps Self-Interest

\section{Data Availability Statement}

The data that support this article are available at:

https://osf.io/ca37t/?view_only=a2080dc11e9e4a59bf61c403d7aef44f. 
Running Head: Ideology Trumps Self-Interest

\section{References}

Ben Casselman, \& Tankersly, J. (2019). Faster Tax Cuts Could Be Backfiring on RepublicansThe New York Times. https://www.nytimes.com/2019/03/21/business/economy/taxrefund-republicans.html

Bernard, T. S. (2019). Smaller Tax Refunds Surprise Those Expecting More Relief. The New York Times. https://www.nytimes.com/2019/02/12/your-money/tax-refund-decrease.html

Bisgaard, M. (2015). Bias will find a way: Economic perceptions, attributions of blame, and partisan-motivated reasoning during crisis. The Journal of Politics, 77(3), 849-860.

Chong, D., Citrin, J., \& Conley, P. (2001). When self-interest matters. Political Psychology, 22, $541-570$.

C.K. (2018, June 5). Why people vote against their economic interests. The Economist. https://www.economist.com/democracy-in-america/2018/06/05/why-people-vote-againsttheir-economic-interests

Cohen, F., Solomon, S., \& Kaplin, D. (2017). You're hired! Mortality salience increases American's support for Donald Trump. Analyses of Social Issues and Public Policy, 17, $339-357$.

Cushman, F. (2020). Rationalization is rational. Behavioral and Brain Sciences, 43.

De La O, A. L., \& Rodden, J. A. (2008). Does religion distract the poor? Income and issue voting around the world. Comparative Political Studies, 41(4-5), 437-476.

Diamond, J. (2016). Trump: I could'shoot somebody and I wouldn't lose voters'. CNN, Sunday, January, 24. 
Dixon, R. D., Lowery, R. C., Levy, D. E., \& Ferraro, K. F. (1991). Self-interest and public opinion toward smoking policies; a replication and extension. Public Opinion Quarterly, $55,241-254$.

Federico, C. M., Golec, A., \& Dial, J. L. (2005). The relationship between the need for closure and support for military action against Iraq: Moderating effects of national attachment. Personality and Social Psychology Bulletin, 31(5), 621-632.

Festinger, L. (1962). A theory of cognitive dissonance (Vol. 2). Stanford university press.

Gaines, B. J., Kuklinski, J. H., Quirk, P. J., Peyton, B., \& Verkuilen, J. (2007). Same facts, different interpretations: Partisan motivation and opinion on Iraq. The Journal of Politics, 69(4), 957-974.

Green, D. P., \& Gerken, A. E. (1989). Self-interest and public opinion toward smoking restrictions and cigarette taxes. Public Opinion Quarterly, 53(1), 1-16.

Hardin, R. (2015). Collective action. RFF Press.

Hart, W., Albarracín, D., Eagly, A. H., Brechan, I., Lindberg, M. J., \& Merrill, L. (2009). Feeling Validated Versus Being Correct:A Meta-Analysis of Selective Exposure to Information. Psychological Bulletin, 135(4), 555-588. https://doi.org/10.1037/a0015701

Hunt, C. V., Kim, A., Borgida, E., \& Chaiken, S. (2010). Revisiting the self-interest versus values debate: The role of temporal perspective. Journal of Experimental Social Psychology, 46, 1155-1158.

Jost, J. T. (2017). Working class conservatism: A system justification perspective. Current Opinion in Psychology, 18, 73-78.

Jost, J. T., \& Banaji, M. R. (1994). The role of stereotyping in system-justification and the production of false consciousness. British Journal of Social Psychology, 33(1), 1-27. 
Jost, J. T., Banaji, M. R., \& Nosek, B. A. (2004). A decade of system justification theory: Accumulated evidence of conscious and unconscious bolstering of the status quo. Political Psychology, 25, 881-919.

Jost, J. T., Glaser, J., Kruglanski, A. W., \& Sulloway, F. J. (2003). Political conservatism as motivated social cognition. Psychological Bulletin, 129, 339-375.

Jost, J. T., Langer, M., Badaan, V., Azevedo, F., Etchezahar, E., Ungaretti, J., \& Hennes, E. P. (2017). Ideology and the limits of self-interest: System justification motivation and conservative advantages in mass politics. Translational Issues in Psychological Science, 3, e1-e26.

Kahan, D. M., Braman, D., Gastil, J., Slovic, P., \& Mertz, C. K. (2007). Culture and identityprotective cognition: Explaining the white-male effect in risk perception. Journal of Empirical Legal Studies, 4, 465-505.

Kay, A. C., \& Jost, J. T. (2003). Complementary justice: Effects of "poor but happy" and "poor but honest" stereotype exemplars on system justification and implicit activation of the justice motive. Journal of Personality and Social Psychology, 85, 823.

Knoke, D. (1979). Stratification and the dimensions of American political orientations. American Journal of Political Science, 23, 772-791.

Kunda, Z. (1990). The case for motivated reasoning. Psychological Bulletin, 108(3), 480.

Lau, R. R., \& Sears, D. O. (1981). Cognitive links between economic grievances and political responses. Political Behavior, 3, 279-302.

Lewis-Beck, M. S., Norpoth, H., Jacoby, W. G., \& Weisberg, H. F. (2008). The American voter revisited. University of Michigan Press.

Miller, W. E. (1991). Party identification, realignment, and party voting: Back to the basics. 
Ideology Trumps Self-Interest

American Political Science Review, 85, 557-568.

Nam, H. H., Jost, J. T., \& Van Bavel, J. J. (2013). "Not for all the tea in China!” Political ideology and the avoidance of dissonance-arousing situations. PloS One, 8, e59837.

Redlawsk, D. P., Civettini, A. J., \& Emmerson, K. M. (2010). The affective tipping point: Do motivated reasoners ever "get it"?. Political Psychology, 31(4), 563-593.

Sears, D. O., \& Citrin, J. (1982). Tax revolt: Something for nothing in California. Harvard University Press.

Sears, D. O., \& Funk, C. L. (1991). The role of self-interest in social and political attitudes. In Vol. 24, pp 1-91. Advances in experimental social psychology. Elsevier.

Sears, D. O., Lau, R. R., Tyler, T. R., \& Allen, H. M. (1980). Self-interest vs. Symbolic politics in policy attitudes and presidential voting. American Political Science Review, 74, 670684.

Sherrin, N. (2008). Oxford dictionary of humorous quotations. Oxford University Press.

Slothuus, R., \& Bisgaard, M. (2021). Party over Pocketbook? How Party Cues Influence Opinion When Citizens Have a Stake in Policy. American Political Science Review, 1-7.

Swire-Thompson, B., Ecker, U. K., Lewandowsky, S., \& Berinsky, A. J. (2019). They might be a liar but they're my liar: Source evaluation and the prevalence of misinformation. Political Psychology.

The Editorial Board, T. E. B. (2017). Opinion | The Tax Bill That Inequality Created. The New York Times. https://www.nytimes.com/2017/12/16/opinion/sunday/tax-bill-inequalitycreated.html

Van Bavel, J. J., \& Pereira, A. (2018). The partisan brain: An Identity-based model of political belief. Trends in Cognitive Sciences, 22, 213-224. 
Ideology Trumps Self-Interest 
Running Head: Ideology Trumps Self-Interest

Table 1. Tax Discrepancy Score and Other Predictors of Trump Support at Time 2.

Model 1. Tax Discrepancy Score, Condition, System Justification, and Political Orientation as Predictors of Trump Support

\begin{tabular}{|c|c|c|c|c|}
\hline Independent Variable: & B & $p$ & $\boldsymbol{\beta}$ & $95 \% \mathrm{CI}$ \\
\hline Tax Discrepancy Score & 0.05 & 0.284 & 0.00 & {$[0.00,0.00]$} \\
\hline Condition & 0.04 & 0.330 & 0.10 & {$[-0.10,0.29]$} \\
\hline Political Orientation & 0.47 & $<0.001 * * *$ & 0.9 & {$[0.73,1.08]$} \\
\hline System Justification & 0.29 & $<0.001 * * *$ & 0.46 & {$[0.32,0.60]$} \\
\hline Tax Discrepancy Score x System Justification & 0.01 & 0.872 & 0.00 & {$[0.00,0.00]$} \\
\hline Condition x Political Orientation & -0.15 & $0.001 * * *$ & -0.28 & {$[-0.45,-0.11]$} \\
\hline Condition x System Justification & 0.01 & 0.791 & 0.02 & {$[-0.12,0.16]$} \\
\hline Tax Discrepancy Score x Condition x Political Orientation & -0.02 & 0.627 & 0.00 & {$[0.00,0.00]$} \\
\hline Tax Discrepancy Score x Condition x System Justification & -0.03 & 0.482 & 0.00 & {$[0.00,0.00]$} \\
\hline Tax Discrepancy Score x Condition x Political Orientation x System Justification & -0.01 & 0.895 & 0.00 & {$[0.00,0.00]$} \\
\hline
\end{tabular}

Note. $\mathrm{n}=334$. All variables were mean-centered. $\mathrm{R}^{2}=0.41$. 
Running Head: Ideology Trumps Self-Interest

Table 2. Tax Outcome Satisfaction and other Predictors of Trump Support at Time 2.

Model 2. Tax Outcome Satisfaction, Condition, System Justification, and Political Orientation as Predictors of Trump Support

\begin{tabular}{|c|c|c|c|c|}
\hline Independent Variable: & B & $p$ & $\boldsymbol{\beta}$ & $95 \% \mathrm{CI}$ \\
\hline Tax Outcome Satisfaction & 0.09 & $0.044^{*}$ & 0.07 & {$[0.00,0.13]$} \\
\hline Condition & 0.03 & 0.463 & 0.07 & {$[-0.12,0.26]$} \\
\hline Political Orientation & 0.45 & $<0.001 * * *$ & 0.87 & {$[0.70,1.05]$} \\
\hline System Justification & 0.27 & $<0.001 * * *$ & 0.43 & {$[0.29,0.58]$} \\
\hline Tax Outcome Satisfaction x Political Orientation & -0.06 & 0.175 & -0.04 & {$[-0.10,0.02]$} \\
\hline Tax Outcome Satisfaction x System Justification & 0.04 & 0.338 & 0.02 & {$[-0.02,0.07]$} \\
\hline Condition x Political Orientation & -0.16 & $0.001 * * *$ & -0.3 & {$[-0.48,-0.13]$} \\
\hline Condition x System Justification & 0.01 & 0.742 & 0.02 & {$[-0.12,0.17]$} \\
\hline Tax Outcome Satisfaction x Condition x Political Orientation & 0.03 & 0.534 & 0.02 & {$[-0.04,0.08]$} \\
\hline Tax Outcome Satisfaction x Condition x System Justification & 0.03 & 0.505 & 0.02 & {$[-0.03,0.06]$} \\
\hline Tax Outcome Satisfaction x Condition x Political Orientation x System Justification & 0.06 & 0.239 & 0.02 & {$[-0.01,0.05]$} \\
\hline
\end{tabular}

Note. $\mathrm{n}=334$. All variables were mean-centered. $\mathrm{R}^{2}=0.41$. 

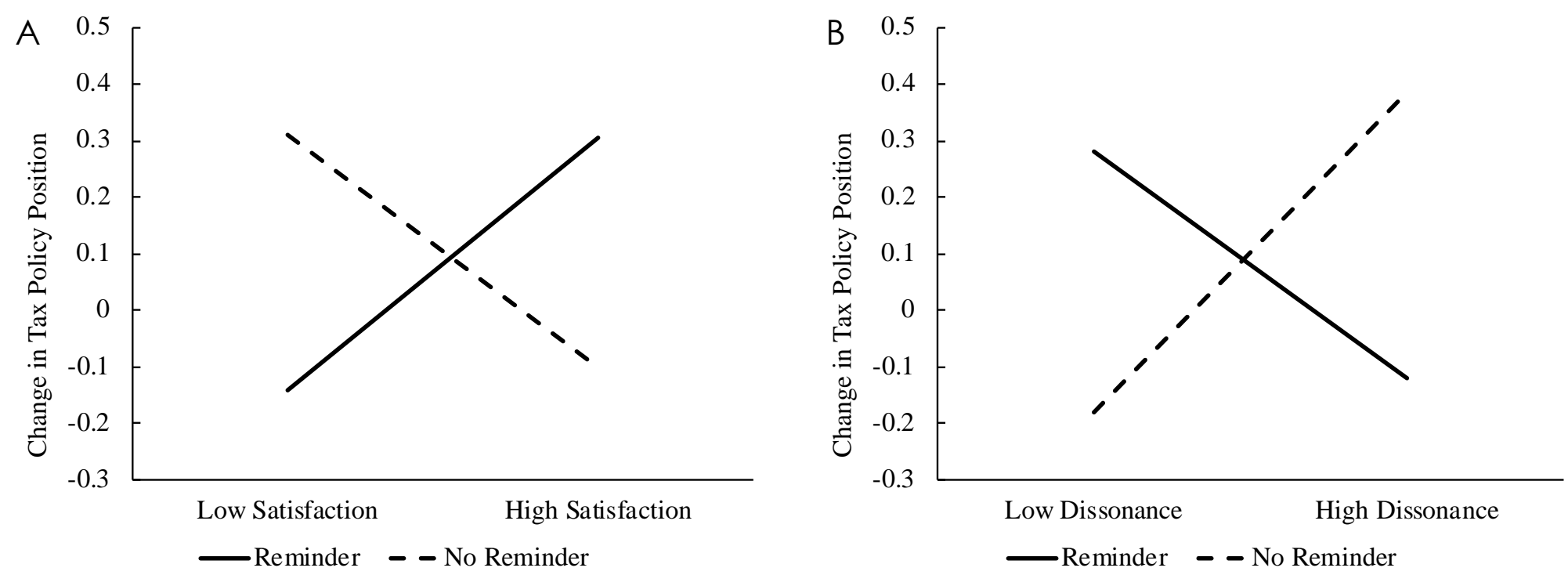

Figure 1. Panel A: Change in tax policy importance as a function of satisfaction with one's tax outcome, and tax reminder condition, with lower scores reflecting a reduction in importance from Time 1 to Time 2 . High versus low satisfaction represents \pm 1 SD from the mean. Panel B: Change in tax policy importance as a function of the cognitive dissonance score (i.e. Trump Support - Tax Outcome Satisfaction) in the reminder vs. no tax reminder conditions. High versus low "dissonance score" represents \pm 1 SD from the mean. 